\title{
Estilística Léxica e o Discurso Jurídico nas Sentenças da Vara Maria da Penha no Combate à Violência Doméstica Contra a Mulher
}

\author{
Lexical stylistic and the Legal Discourse in the Sentences of \\ the "Vara Maria da Penha" in the Combat the Domestic \\ Violence Against the Women
}

\author{
Claudete Carvalho CANEZIN ${ }^{1}$ \\ Edina Regina Pugas PANICHI ${ }^{2}$
}

\begin{abstract}
RESUMO: É o presente artigo um estudo acerca da estilística léxica nos discursos jurídicos das sentenças que envolvem a violência contra a mulher na Vara Maria da Penha, na comarca de Londrina-Paraná. Assim como o Direito, a linguagem é uma instituição social reguladora das relações humanas, funcionando, portanto, como mediadora entre a pessoa e a realidade cotidiana que a cerca. Infelizmente, em muitas situações, a linguagem é utilizada de forma nociva, donde é possível vislumbrar itens lexicais e avaliativos utilizados de forma pejorativa, tal como acontece em músicas, propagandas, e até mesmo em piadinhas de mau gosto que circulam nas redes sociais e que acaba camuflando a agressividade contra a mulher, violência esta que não precisa ser especificamente física, mas também moral e psicológica, e, neste contexto, as palavras são armas poderosas. A fim de coibir a violência contra a mulher, foi editada a Lei no 11.340/2006, conhecida como Lei Maria da Penha. A partir de sua promulgação, todos os processos envolvendo violência de gênero passaram a tramitar nos Juizados Especiais Criminais da Varas Maria da Penha. Pretende-se, pois, através da análise da estilística léxica, voltar olhares e trazer para a pauta do estudo a análise de itens lexicais e avaliativos comuns no discurso jurídico das sentenças dos processos que tramitam na Vara Maria da Penha, inclusive, com a transcrição de parte dos relatórios, preservando as partes envolvidas por se tratar de segredo de justiça.
\end{abstract}

PALAVRAS-ChAVe: Estilística léxica. Discurso jurídico. Sentenças. Violência doméstica.

ABSTRAT: This article is a study about lexical stylistics in the legal discourses of sentences involving violence against women in the "Vara Maria da Penha", Londrina, Paraná. Like Law, language is a social institution that regulates human relations, functioning, therefore, as a mediator between the person and the everyday reality that surrounds him. Unfortunately, in many situations, the language is used in a harmful way, where it is possible to glimpse lexical and evaluative items used in a pejorative

\footnotetext{
${ }^{1}$ Doutoranda em Estudos da Linguagem-PPGEL/UEL. Mestre em Direito. Especialista em Direito Empresarial. Graduada em Direito. Professora de Direito Civil na Graduação e Pós Graduação da UEL. Advogada.

2 Professora Senior do Programa de Pós Graduação da UEL- PPGEL.
} 
way, as in music, advertisements, and even in bad taste jokes that circulate in social networks and that End up camouflaging violence against women, violence that does not have to be specifically physical but also moral and psychological, and in this context words are powerful weapons. In order to curb violence against women, Law $11.340 / 2006$, known as the Maria da Penha Law, was issued. From its promulgation, all processes involving gender violence began to process in the specialized rods Maria da Penha. It is intended, therefore, through the analysis of lexical stylistics, to look back and to bring to the agenda of the study the analysis of lexical and evaluative items common in the legal discourse of the sentences of the processes that process in the "Vara Maria da Penha", including, with the transcription of the reports, preserving the parties involved because it is a matter of.

KEYWORDS: Lexical stylistics. Legal discourse. Sentences. Domestic violence.

\section{Introdução - A Violência Doméstica Contra a Mulher}

É possível perceber que a violência de gênero contra as mulheres não é assunto recente, é prática antiga e encontra-se historicamente ligada ao lugar social que o Estado e a sociedade determinavam para elas, ou seja, eram submissas aos pais e ou aos maridos, sempre consideradas propriedade de algum homem, não tinham capacidade civil ou qualquer poder sobre a família, nos moldes do antigo pátrio poder.

Após as grandes revoluções, as mulheres ganharam espaço no cenário social, porém continuam lutando pela conquista de seus direitos e contra uma cultura de dominação masculina. Atualmente, a despeito de poucos exemplos, elas começaram a ocupar lugar de poder na sociedade. Apesar das conquistas, continuam sendo vítimas de violência doméstica, de preconceitos e de muitos estereótipos. Por mais que se lute, o considerado sexo frágil ainda sofre o peso de um passado sexista.

A violência sempre ocupou um lugar de destaque na sociologia nacional, principalmente por enfocar o tema da distribuição e do exercício do poder. Coube ao estudo do gênero demonstrar a existência de uma modalidade específica de violência, aquela que se origina no modo como se armam as relações entre homens e mulheres no âmbito doméstico e familiar.

Quase a totalidade dos casos de mulheres que sofrem agressão é causada por homens que integram o grupo doméstico e/ou familiar da mulher, 
como maridos, companheiros, pais, padrastos e namorados. Infelizmente, as estatísticas de vitimização feminina são contundentes no sentido de assinalar que a estrutura da conjugalidade em particular, e a da família em geral, no que implica uma ordenação de gênero, abriga uma virtualidade de violência.

Ednilsa Souza apresenta um conceito bastante oportuno sobre a violência ao descrevê-la como "um fenômeno gerado nos processos sociais, que atinge os âmbitos das instituições, grupos e indivíduos, sendo desigualmente distribuída, culturalmente delimitada, e reveladora das contradições e das formas de dominação na sociedade" (SOUZA, 1996, p. 31).

Entendida, pois, como um ato que impossibilita ao outro manifestar suas vontades, a violência revela-se como um conversor de diferenças e relações assimétricas no sentido de impor uma ideologia, um comportamento, mesmo que para isso seja preciso dominar e oprimir o outro.

Especificamente no caso brasileiro, e do ponto de vista histórico e cultural, a violência doméstica contra a mulher é vista como uma herança cultural, fruto de uma sociedade escravocrata, a partir de um modelo colonizador que aqui se instalou e pregou a hierarquia e o preconceito (MARCONDES FILHO, 2000).

Em 1994 a OEA, Organização dos Estados Americanos, aprovou a Convenção de Belém do Pará, ratificada posteriormente pelo Brasil, em 1995, para prevenir, punir e erradicar a violência contra a mulher. A convenção estabelece que se constituem violência contra a mulher "o assédio sexual, a violência racial, a violência contra mulheres idosas e a revista íntima, dentre outras modalidades" (CRUZ, 2004, p. 32). Assim, o conceito de violência contra a mulher deve ser fundamentado na Convenção de Belém do Pará e diz respeito a

[...] qualquer ato ou conduta baseada no gênero, que cause dano, morte, constrangimento, limitação, sofrimento físico, sexual, moral, psicológico, social, político, econômico ou perda patrimonial à mulher, tanto na esfera pública como na esfera privada. Assim, a violência contra a mulher é qualquer conduta - ação ou omissão - de discriminação, agressão ou coerção, 
ocasionada pelo simples fato de a vítima ser mulher (CRUZ, 2004, p. 34).

Dúvidas não há de que toda e qualquer forma de violência traz consequências avassaladores para a vítima. Isto porque além das lesões físicas, que incluem dores crônicas e incapacidade física, também as lesões psicológicas são difíceis de serem cicatrizadas, motivos pelos quais a violência doméstica, em todas as suas manifestações, tem sido considerada um problema de saúde pública (LANGREY, 1980).

Foi especialmente a partir da década de 1970 que a questão da violência doméstica se transferiu do espaço privado para o espaço público, passando a ser encarada como um problema social a combater. Países inteiros se mobilizaram no intuito de criar propostas destinadas a enfrentar este flagelo social. Apesar de todo o avanço neste sentido, os meios de combate à violência doméstica, no tocante às políticas públicas, são ainda insuficientes. O combate à violência contra a mulher exige uma ação integrada da sociedade, exigindo políticas públicas, decididas e devidamente apoiadas, e uma maior participação das mulheres agredidas.

Apesar de alguns avanços na seara legislativa, os grandes avanços nas formas de relacionamento interpessoal nas diversas culturas e nas leis de cada país ainda não são capazes de impedir que crimes primitivos e brutais continuem a acontecer com uma frequência assustadora pelo mundo. É certo que os registros de casos engrossam a cada dia as estatísticas, motivados por políticas que encorajam as vítimas a denunciarem seus agressores, mas ainda não traduzem a realidade.

Em 2006, a legislação ouviu os anseios da sociedade no sentido de promulgar uma lei específica a fim de coibir os casos de violência contra a mulher. Foi quando surgiu a Lei Maria da Penha, que despontou num contexto social marcado pela persistente diferença de gênero, vindo como um meio para coibir a cultura da violência e dos preconceitos contra a mulher. Conforme a Lei Maria da Penha, Lei no 11.340/2006, art. 50, configura-se como violência 
doméstica contra a mulher "qualquer ação ou omissão baseada no gênero que Ihe cause morte, lesão, sofrimento físico, sexual ou psicológico e dano moral ou patrimonial" (BRASIL, 2006).

A violência de gênero contra a mulher deve ser reprimida, uma vez que qualquer forma de violência deixa cicatrizes muito difíceis de serem reparadas, seja no aspecto físico, seja no psicológico e emocional. Este tipo de violência não escolhe vítima, afetando as mulheres independente de sua classe social, raça, religião, etnia, grau de escolaridade ou idade. A mulher precisa ser respeitada em sua essência. Precisa ser vista e reconhecida como ser humano que é, individual, peculiar, dotada de ideologias, preferências, vaidades. É preciso permitir à mulher viver, acima de tudo, com dignidade.

\section{As Vozes Sociais que Camuflam a Violência Doméstica}

A violência contra a mulher pode ser retratada em situações que estão presentes no cotidiano das famílias e da sociedade. Propagandas e letras de música, por exemplo, utilizam certas expressões que podem passar, erroneamente, a ideia de que determinadas situações são admissíveis, quando na realidade não o são.

Como afirma Marcuschi (2007), se "a língua é uma fonte de possibilidade de trabalhar e retrabalhar as versões públicas do mundo deve-se pensar o domínio da linguagem e o musical como um instrumento não transparente". Em outras palavras, é preciso que as letras das músicas e propagandas sejam vistas como instrumento de diversão e, por que não, de informação, nunca de incitação a qualquer tipo de discriminação ou violência de gênero, como é a violência contra a mulher. (CANEZIN; PANICHI, 2016a).

$\mathrm{O}$ discurso da violência de gênero circula na sociedade há muito tempo e através de diferentes materialidades linguísticas. Determinados enunciados constroem uma imagem deturpada da mulher. Muitas vezes a mesma é associada a questões relacionadas à casa, à comida ou aos filhos por exemplo, 
passando a imagem de que o lugar da mulher é em casa, cozinhando ou cuidando dos filhos.

Um exemplo é a imagem abaixo que viralizou na internet ${ }^{3}$ nos últimos dias, próximo às comemorações do Dia Internacional da Mulher, 08 de março. $\mathrm{O}$ que num primeiro momento pode parecer uma simples brincadeira, deixa claro um pensamento e comportamento machista que ainda nos dias atuais associa a imagem da mulher tão somente às atividades do lar, como se fosse uma escrava doméstica e sexual.

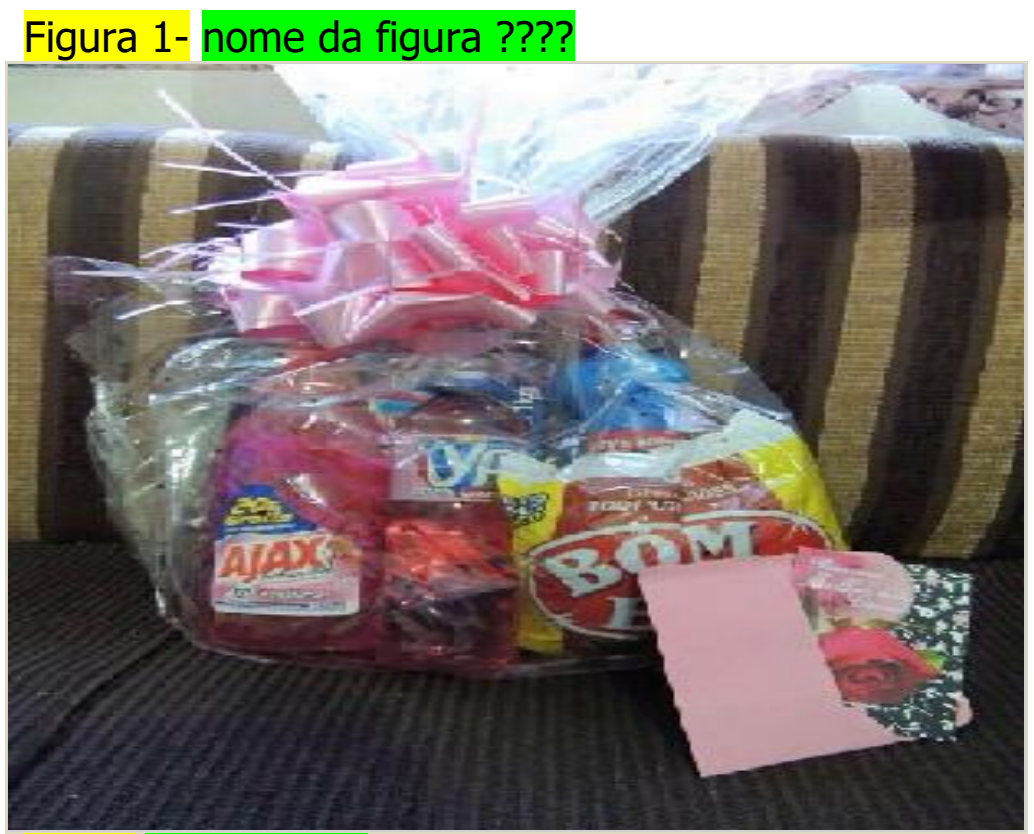

Fonte: tirou de onde?

Isto traz à tona a noção de que, sob diferentes formas, o discurso da violência contra a mulher, mesmo que camuflado, acaba se manifestando de maneira disfarçada e amenizada. É possível presenciar tal violência implícita em letras de músicas que trazem um apelo sensual ou sexual, por exemplo. Nestas composições são empregados muitos diminutivos que têm conotações sensuais, ou seja, palavras afetuosas usadas para designar o que é agradável, e segundo Veríssimo (2017), "aquelas coisas tão afáveis que se deixam diminuir sem

\footnotetext{
${ }^{3}$ Divulgado nos aplicativos de mídia social em março 2017 - facebook e whatsApp.
} 
perder o sentido". A sensualidade, o excitante da imaginação e o erótico estão presentes nas músicas de forma explícita.

O sufixo diminutivo é um recurso estilístico que torna a linguagem mais afetiva e mais expressiva, refletindo os nossos sentimentos pelas coisas e pelas pessoas. É nestes sufixos que a descarga das emoções e das intenções se dá com maior energia (LAPA, 1982). Em muitas letras de músicas é possível vislumbrar a violência contra a mulher associada ao prazer sexual, produzindo a imagem de uma mulher que pede para apanhar porque isso a deixa maluquinha e que pede tapa na cara quando faz amor.

Ao ser colocada dessa maneira, a violência deixa de ser considerada uma responsabilidade do agressor e passa a ser uma responsabilidade da mulher agredida: é ela quem pede, é ela quem quer, é ela quem gosta; não há culpa, portanto, da parte de quem agride. Quando numa canção de Sidney Magal (1977) Se te agarro com outro te mato: Se te agarro com outro / Te mato! / Te mando algumas flores / $E$ depois escapo..., isso passa a ser tolerado socialmente. (CANEZIN; PANICHI, 2016a).

Esse discurso acaba por chancelar a violência do homem contra a mulher e, cantada em paradas musicais, passa a ser repetido, a ser tomado como normal e a esconder certa conivência da sociedade para com a violência doméstica. Quando na letra de uma música popular se menciona um comportamento violento, se banaliza a opressão, fazendo parecer que aquele comportamento é normal. De certa forma, isso estimula as agressões. (CANEZIN; PANICHI, 2016a).

Desde os tempos remotos é possível perceber uma fala social seja em brincadeiras publicitárias, como a mencionada que viralizou nas redes sociais, seja em letras de músicas ou até mesmo em uma roda de amigos onde se utilizam adjetivos ou expressões pejorativas para se referir à mulher, como por exemplo biscate, vagabunda ou gostosona. Essas falas têm a clara intenção de inferiorizar a mulher, de colocá-la à margem da sociedade, uma vez que, 
obviamente, são termos que evocam o preconceito e entoam um discurso violento.

Essas falas sociais tentam rebaixar as mulheres apegando-se a vários aspectos como a vaidade, a autoestima, o mercado profissional e a dependência econômica. Em uma sociedade em que a beleza dita valores, é possível compreender como essas questões podem afetar o estado psicológico feminino. É uma tentativa de depreciar a feminilidade, diminuindo a mulher, fazendo com que esta tenha sua autoestima aviltada e, portanto, sinta-se inferior, sinta-se incapaz de ser amada e aceita pelo outro. (CANEZIN; PANICHI, 2016b).

A mulher é colocada como dependente, econômica e emocionalmente. Quando não está inserida no mercado de trabalho, seu valor se perde ainda mais. Cuidar da casa e da família nada representa na visão do marido que, agressivamente, coloca a mulher em situaçao de acomodada, de inútil, fazendo-a sentir-se incapaz de sobreviver sozinha. Discurso jocoso, brincadeirinhas e piadas de mau gosto, discurso de baixo calão, tudo isso são maneiras de perceber as marcas da violência de gênero disseminadas na sociedade, utilizadas como forma de difundir o ódio.

\section{Estilística Léxica e o Discurso Jurídico}

O estilo está intimamente ligado às escolhas do autor, uma vez que uma mesma frase pode ser escrita ou falada de maneiras diferentes. Neste sentido, "cada ato de significação é uma construção imediata à experiência e deflagra uma relação interpessoal. É a conjunção do experiencial com o interpessoal. Assim, os atos de significação são atos de identidade e ocorrem em contextos específicos". (REI; SIMÕES, 2014, p. 447).

As formas de expressão, portanto, são objeto da estilística, por meio da observação do uso da língua e seus recursos gramaticais, semânticos ou lexicais. Contudo, deve-se ficar atento para o fato de que "um estilo não se detecta na simples comparação de um texto frente a uma regra ou a um 
dispositivo qualquer; é preciso haver um relacionamento intertextual". (BRITO; PANICHI, 2013, p. 123).

Nilce Sant'Anna Martins (2012) argumenta que Bally, um dos precursores das pesquisas sobre os fenômenos de sensibilidade que se manifestam no uso da língua e que estão além do que a gramática normativa consegue definir, identificou conceitos subjetivos na fala e na escrita que expressam sentimentos e evocam ideias. Evidencia a autora que Bally não se volta para o discurso, para o uso individual da língua, mas para o sistema expressivo da língua coletiva, iniciando, assim, uma Estilística da expressão linguística, no sentido de desconsiderar os estilos individuais e valorizar o que leva o ser humano a revelar sentimentos, afetividade ou estado emocional. Assim, é possível destacar que a Estilística é uma das disciplinas voltadas para os fenômenos da linguagem, tendo por objetivo analisar os efeitos da afetividade nos atos da fala.

A Estilística ultrapassa os estudos da Retórica uma vez que não se limita a explicar os valores denotativos da língua, mas também os estados emotivos e psíquicos que despertam no receptor reações afetivas. É possível reconhecer na linguagem uma dupla função: uma representativa (referencial, denotativa), que se volta a um conteúdo objetivo; e outra função expressiva, que se refere ao conteúdo subjetivo e que constitui o fato estilístico. (MARTIN, 2003).

É preciso se ter em mente, portanto, que o resultado estilístico depende da associação entre os recursos da gramática. Do mesmo modo, a expressividade da língua decorre da capacidade em estimular a imaginação do interlocutor através dos signos que representam alguma mensagem que está subscrita além do texto. Sozinha, a palavra não tem força, mas ganha sentido de acordo com a intenção com a qual é utilizada.

Segundo José Lemos Monteiro as nuances de emotividade estão associadas na memória a experiências e impressões afetivas:

São os componentes afetivos do significado, em qualquer plano da linguagem, que instauram a atmosfera conotativa. A 
denotação, ao contrário, é ligada ao aspecto conceitual. Há palavras que, usadas em determinados contextos ou justapostas a outras unidades, despertam sentimentos e aguçam a memória individual ou coletiva. Assim, as palavras podem transmitir sensações a partir da relação involuntária entre elementos materiais e imateriais. (MONTEIRO, 1991, p. 19).

A Estilística da palavra, ou Estilística léxica, estuda os aspectos expressivos das palavras ligados aos seus componentes semânticos e morfológicos, aliados ao nível sintático e suas formas de uso e composição. Os atos da fala resultam da combinação de palavras, segundo as normas linguísticas. Neste sentido, não se pode ter uma perfeita definição de uma palavra, analisando-a isoladamente. É preciso que esta esteja inserida em um contexto para se reconhecer seu real significado.

Brito e Panichi esclarecem que as "sensações provocadas pelo léxico não possuem o mesmo peso ou colorido para todos os falantes, pois os sentimentos variam de uma pessoa para outra, de época para época, de grupo social para grupo social, de situação ou de contexto. (BRITO; PANICHI, 2013, p. 126).

Quando aplicada ao campo jurídico, a linguagem se reveste de uma tipologia especifica, "que é a do poder e da persuasão, permeado pelo elemento ideológico" (BRITO; PANICHI, 2013, p. 12). Assim, o discurso deve observar algumas particularidades, uma vez que lida com valores sociais, éticos e morais. Neste caso específico, por ser objeto do presente estudo, nos limitaremos ao discurso jurídico.

De forma simplificada é possível dizer que o universo jurídico é composto pelos fatos cotidianos da vida que, quando analisados como relevantes, são normatizados e passam a ser considerados fatos jurídicos. O Direito, então, passa a tutelar estes fatos gerando direitos, deveres, pretensões, obrigações e efeitos jurídicos e, enfim, passam a ter efeito vinculante da conduta humana.

Assim como o Direito, também a linguagem é uma instituição social. Saussure discorre que a linguagem é fundadora da sociedade e das relações intersubjetivas sendo, ao mesmo tempo, realidade psíquica e instituição social. 
Isto porque ao mesmo tempo em que é um produto social da faculdade da linguagem, é também um conjunto de convenções adotadas pela sociedade com vistas a permitir o exercício dessa faculdade nos indivíduos (SAUSSURE, 2002). Possível entender, portanto, que tanto a linguagem quanto o direito são instituições sociais mediadoras das relações humanas.

A linguagem funciona como meio de interação entre o indivíduo e a sociedade, sendo que é por seu intermédio que a realidade se transforma em signos, através da associação de significantes sonoros a significados. É através da linguagem que é possibilitado ao indivíduo articular um discurso específico para cada ocasião.

O Direito desenvolveu ao longo dos tempos práticas e rotinas extremamente institucionalizadas e exclusivas. Desenvolveu, também, uma linguagem própria e peculiar "com utilização de jargões, que também servem para concentrar e reunir em uma única palavra determinados conceitos que poderiam exigir até mesmo uma frase inteira para serem explicados", caracterizando-se como uma linguagem específica (FIGUEIREDO, 2015).

A linguagem forense, portanto, possui particularidades que a tornam um dialeto inconfundível com os demais do cotidiano do falante, fazendo com que seja uma linguagem complexa, acessível a uma pequena parcela da comunidade, o que dificulta o acesso àqueles que pleiteiam a justiça, retardando a prestação jurisdicional.

Importante destacar que, por se tratar de uma área que dita regras de comportamento social, estabelecendo direitos e obrigações entre os indivíduos, o discurso jurídico reveste-se de um caráter voltado à ética e aos bons princípios. Igualmente, o discurso jurídico caracteriza-se pela utilização de termos técnicos em praticamente todas as suas aplicações, o que torna a linguagem específica e complexa, incompreensível, na grande maioria das vezes, aos falantes (BRITO, 2009).

O texto forense é conduzido por expressões arcaicas presentes nas petições e que, ao lado da linguagem rebuscada e técnica. 
[...] ajuda a sustentar a concepção de que a linguagem do poder dá "prestígio" àquele que a emprega e, por isso, tem maior poder de convencimento, já que, na sua elaboração e por meio de seus termos específicos, impressiona o ouvinte que, se estiver em esfera social diferente, sente-se "impotente" para contra-argumentar (BRITO, 2009).

O discurso jurídico apresenta certas peculiaridades que resultam numa linguagem própria, técnica. Assim, a linguagem dos operadores do direito é muito particular, o que implica num léxico peculiar dessa área de atuação humana. Popularmente, essa linguagem forense é chamada de "juridiquês", sendo que qualquer pessoa alheia a esse universo jurídico terá grandes dificuldades para compreender palavras e expressões especializadas, motivo pelo qual alguns defendem a extinção deste tipo de linguagem, tão rebuscada, alegando um entrave ao acesso à justiça.

Por meio do estudo das sentenças oriundas dos processos da Vara Maria da Penha, pretendemos melhor compreender a esfera de atividade jurídica, suas finalidades e condições específicas, bem como analisar as escolhas lexicais presentes nestas decisões.

\section{Estilística Léxica e Análise nas Sentenças da Vara Maria da Penha}

José Lemos Monteiro discorre que sem desprezar noções de desvio e escolhas, o estudo estilístico costuma estar relacionado aos elementos capazes de despertar conteúdos emotivos. (MONTEIRO, 2009). Câmara Júnior acrescenta que nem toda peculiaridade linguística de um escritor constitui um fato de estilo, mas somente aquela que for utilizada para fins de exteriorização psíquica. (CÂMARA JÚNIOR, 1978). As palavras, portanto, têm uma significação extralinguística, capaz de despertar em nossa mente uma representação, seja de seres, de ações, ou sentimentos, uma vez que remetem a algo que está fora da língua e que faz parte do mundo físico, psíquico e social. 
O universo psíquico caracterizado pelos sentimentos e emoções é vasto e múltiplo. Assim, o uso de determinadas das palavras ou as escolhas lexicais são capazes de traduzir os valores emotivos dos enunciados, exteriorizando as intenções dos falantes e, segundo José Brasileiro Vilanova:

\begin{abstract}
A tonalidade afetiva de uma palavra pode estar ser inerente ao próprio significado, ou seja, a palavra em si já causa alguma reação ou emoção na pessoa, ou pode resultar de um emprego particular sendo perceptível no enunciado em razão do contexto, ou pela entoação (enunciado oral), ou por algum recurso gráfico (enunciado escrito), isto é, dependendo da experiência individual (origem, classe, faixa etária, região), a palavra afetará a pessoa, a vivência faz com que a pessoa tenha empatia ou não com a palavra, tornando-a mais expressiva ou menos expressiva. (VILANOVA, 1984, p. 84).
\end{abstract}

Algumas palavras chamadas afetivas emitem uma carga sentimental, ou emotiva, que são passadas às suas derivações. É preciso conhecer o contexto para se afirmar, com precisão, qual é realmente seu significado. Assim analisálas isoladamente como vocábulo é ignorar a verdadeira intenção de seu uso. Neste sentido:

Seja como for, é inegável que, assim como os valores se sedimentam num dado ambiente social, inúmeros lexemas são portadores de evocações relacionadas à própria cultura. $O$ erro esta apenas em pretender que em todas as situações eles comunicam a mesma expressividade. Por isso, o método estilístico tem que recorrer constantemente à noção de contexto. (MONTEIRO, 2009, p. 53).

De igual maneira, são carregadas de afetividade as palavras que exprimem um julgamento pessoal. Neste caso destacam-se os adjetivos que atribuem qualidades às coisas, sejam elas positivas ou negativas, bem como os substantivos abstratos, verbos e advérbios a eles correspondentes. São igualmente carregadas de carga afetiva um lexema acrescido de um sufixo ou prefixo. Assim, por exemplo, se política, gente, povo podem empregar-se sem tonalidade afetiva em contextos intelectivos, já politicagem, politicalha, 
gentalha, poviléu, são muito mais ricas em afixos responsáveis por uma derivação emotiva de considerável amplitude. (VILANOVA, 1984).

Vale destacar que embora ofereça menores possibilidades, a derivação prefixal também consegue exprimir sentimento, valores. É o caso, por exemplo, de superalegre ou superbondoso. Já os sufixos apresentam maior variedade na língua apresentando uma multiplicidade de valores afetivos, especialmente através do diminutivo e do aumentativo.

A análise de crimes contra a mulher está inserida no que Capez (2005 apud FUZER; BARROS, 2008, p. 48) definiu como sistema de gêneros, ou seja, "uma série ou sequência de atos conjugados que se realizam e se desenvolvem no tempo, destinando-se à aplicação da lei penal no caso concreto". No ambiente jurídico, um gênero segue outro gênero em uma sequência regular e em padrões temporais previsíveis, revelando um fluxo comunicativo típico do grupo que o originou.

Ferraz Júnior acrescenta que "o ato decisório implica uma situação de comunicação, entendida como sistema interativo global, pois decidir é ato sempre referido a outrem, em diferentes níveis recorrentes". (FERRAZ JÚNIOR, 2013, p. 287).

Colares (2008), seguindo as lições de Bakhtin, discorre que as produções linguístico-discursivas, ainda que não o intentem de forma explícita, são determinadas por ideologias, crenças e valores que saturam o discurso de seu enunciador de subjetividade. Sendo assim, toda elaboração legislativa estará inexoravelmente embebida das mais profundas ideologias e hábitos que permeiam o seio social.

Nos processos envolvendo violência contra a mulher, termos empregados pelos operadores do direito revelam o quanto as agressões são extremas. No processo da Vara Maria da Penha de Londrina, Autos no 0011.393-xxx (segredo de justiça), processo em análise, página 3 da Pronúncia, no relato dos fatos, lêse a seguinte informação: 
[...] o denunciado "fulano de tal" praticou violência de gênero contra sua ex-mulher, por motivo torpe, em razão de não se conformar com o término de seu relacionamento. Outrossim, o crime de homicídio tentado foi praticado mediante meio cruel vez que o denunciado desferiu sete golpes de faca contra a vítima, inclusive no rosto, evidenciando assim vilania e frieza em seu comportamento, impingindo maior sofrimento à vítima. (Autos 0011.393-xxx Segredo de Justiça). (grifo nosso)

Os termos cruel, vilania, frieza e torpe demonstram a atrocidade do crime, denotando a visão do Ministério Público em relação ao ocorrido. A utilização dos elementos intensificadores da ação cometida foi feita de forma deliberada, no sentido de expressar a morbidez da atitude tomada pelo réu.

Outro exemplo da crueldade do agressor fica evidente na utilização do advérbio inclusive, que demonstra a intenção de ferir, de provocar marcas, de abalar a estética e a autoestima da ex-companheira, ao desferir golpes de faca, inclusive, no rosto da vítima, produzindo cicatrizes dilacerantes no corpo e na alma.

A simples menção desferiu sete golpes de faca contra a vítima já expressaria uma violência extrema, caracterizando o tom da crueldade e da frialdade do ato. Com este recurso, no entanto, o operador do direito cria o espaço afetivo necessário para se olhar o acusado sob o prisma da culpabilidade. Dessa forma a língua, além de fornecer os meios para a comunicação social do indivíduo, dá a ele também a oportunidade de exteriorizar os seus sentimentos, de forma que o alcance representativo dos termos se desdobra num alcance expressivo. Mesmo pretendendo ser a linguagem processual altamente denotativa, ela é passível de escolhas lexicais que buscam convencer e criar a emoção no interlocutor.

Outro trecho do processo em análise, página 2 da Pronúncia, no relato dos fatos, corrobora a violência e a crueldade do agressor ao informar que

[...] iniciada a execução do crime de homicídio, este não se consumou por circunstâncias alheias à vontade do denunciado uma vez que a filha da vítima (xxxxxxx) buscou impedir a ação 
delitiva do denunciado, segurando-o pelas costas e, ao não conseguir contê-lo, correu ao quarto de seu irmão suplicando por sua ajuda. (Autos 0011.393-xxx Segredo de Justiça).

Num primeiro momento é possível observar que o agressor tinha a intenção de levar a agressão às últimas consequências. Isso é possível perceber pela utilização da expressão circunstâncias alheias à vontade. No caso em análise, fica claro que a execução do crime de homicídio foi interrompida não por vontade do agressor, mas por fatores estranhos que fugiram ao seu controle, qual seja a intervenção dos próprios filhos.

Outro aspecto marcante que chama a atenção nos processos que tramitam na Vara Maria da Penha, em Londrina, diz respeito ao trauma que marca os envolvidos numa situação de agressão. A vítima sobreviveu, mas os golpes sofridos deixaram várias cicatrizes em seu rosto, peito e braço, paralisia facial à esquerda e diminuição da acuidade visual, como mencionado na página dois da pronúncia da sentença.

As agressões deixam marcas também nos familiares e nas pessoas próximas à vítima. No caso em análise, a execução do crime de homicídio foi interrompida pela intervenção dos filhos, tal como narrado na página 2 da pronúncia:

[...] a filha da vítima (XXXx) buscou impedir a ação delitiva do denunciado, segurando-o pelas costas e, ao não conseguir contê-lo, correu ao quarto de seu irmão, (xxxxxx) suplicando por sua ajuda. (Autos 0011.393-xxx Segredo de Justiça).

O verbo suplicar, utilizado pelo operador do direito, demonstra o estado emocional da filha que ao presenciar as agressões sofridas pela mãe, implora por ajuda. O verbo suplicar significa pedir humildemente, ou com insistência; pedir; postular; implorar (FERREIRA, 2017), revelando o desespero da filha ao presenciar o próprio pai agredindo friamente sua mãe.

É flagrante, neste trecho, a afetividade refletida nas palavras do enunciador do discurso quando ao narrar os fatos, opta pela forma verbal 
suplicar. Ele poderia ter utilizado qualquer outro sinônimo, como por exemplo, pedir, solicitar, buscar. A substituição de um termo por outro, no entanto, resulta em gradações significativas no entendimento dos fatos. $O$ que faculta um ou outro emprego lexical é a tonalidade afetiva que se busca alcançar em uma determinada situação. Nesse caso, a preferência pela forma verbal suplicar explica-se pela abrangência afetiva que ela traz à construção naquele momento. Sabemos que não há sinônimos perfeitos. Cada palavra é portadora de um sentido que adquire real significado no contexto, pois segundo Lapa: "Podem uma mesma idéia, um mesmo ato, um mesmo objetivo ter nomes diferentes; esses nomes não são, mas podem ser exatamente equivalentes, como não são podem ser equivalentes as folhas da mesma árvore". (LAPA, 1982, p. 18).

Em outro processo da Vara Maria da Penha de Londrina, Autos no 000.7318.xxx (segredo de justiça), processo em análise, página 1 da Pronúncia, no relato dos fatos, lê-se a seguinte informação:

Em 08 de fevereiro de 2014, por volta das 00h30, compareceu a vítima A.K.P. na $10^{\circ}$ Subdivisão Policial de Londrina, localizada na Rua Sergipe, 52, Centro, acompanhada de seus genitores XXX e XXX, (segredo de justiça), a fim de registrar boletim de ocorrência em razão das ameaças de morte proferidas contra ela pelo denunciado, XXXXX, seu exnamorado, poucas horas antes de ser por ele executada [...]. (Autos no 000.7318.xxx, segredo de justiça).

Neste caso é possível ilustrar uma situação bastante comum nos casos de violência contra a mulher. A palavra ameaça deriva de um ato ou gesto pelo qual se exprime a vontade que se tem de fazer mal a alguém. Pode significar, também, um sinal ou uma manifestação que leva a acreditar na possibilidade de ocorrer alguma coisa (FERREIRA, 2017).

É comum nos discursos da Vara Maria da Penha a utilização do substantivo ameaça. É prática comum entre os agressores a fim de intimidar a mulher com a finalidade de assustar, amedrontar, enfim, desestimular que elas 
informem, comuniquem, conversem com alguém a respeito da violência que vêm sofrendo, evitando, assim, a denúncia do agressor.

Ainda nos Relatórios, página 2 , é possível se obter a seguinte informação:

[...] conhecendo o intuito da vítima ao se dirigir à Delegacia de Polícia, o denunciado XXX (segredo de justiça) agindo mediante emboscada, escondeu-se nas proximidades da residência da vítima, localizada na rua XXX, e lá permaneceu aguardando pelo retorno da vítima. Naquela data, por volta da 1 hora, XXX, voltou à sua residência [...] quando o denunciado, dolosamente, ciente da ilicitude e reprovabilidade de sua conduta, com a intenção de matar, utilizando-se de uma arma de fogo [...] efetuou 3 disparos_contra a vítima, mesmo após esta estar caída no chão, tendo, em seguida evadido-se do local. (Autos no 000.7318.xxx, segredo de justiça).

Neste trecho é possível também identificar a crueldade e o sangue frio do agressor, pela utilização do substantivo emboscada. A palavra traz em seu bojo uma conotação negativa, pois envolve a ideia de traição, tocaia, ataque inesperado, ou seja, "o vocábulo sofre o contágio das sensações agradáveis ou desagradáveis que decorrem das próprias coisas [...]" (CÂMARA JUNIOR, 1978, p. 58). Certas sensações se consolidam em torno de determinadas palavras, mesmo que a situação relatada seja tida como referencial, como na ocorrência em análise. Neste caso, o agressor teve a frieza de ficar escondido próximo à casa da vítima esperando que a mesma descesse do carro para só então efetuar os disparos, numa demonstração clara do propósito de cometer o crime.

A intenção de matar e a crueldade do fato são corroborados pelo advérbio de modo dolosamente e pelo substantivo intenção. No texto em questão, o advérbio exprime o modo de agir do agressor, que revelou vontade, intento, e desejo de praticar o ilícito. Igualmente, o substantivo deixa clara a intenção do agressor demonstrando que, mesmo de maneira consciente e tendo conhecimento da ilicitude do ato, o mesmo se escondeu próximo à casa 
da vítima e aguardou o momento exato para dar o bote, tal qual um animal abatendo a sua presa.

Igualmente, quando na sentença é abordada a decisão da Juíza e seus Fundamentos, páginas 6 e 7, é possível obter as seguintes informações colhidas com algumas testemunhas:

[...] o acusado afirmava que iria matar a vítima e a ofendia verbalmente; o acusado efetuava as ameaças em razão do término do relacionamento com a vítima; [...] o acusado estava ameaçando a vítima; [...] o acusado era uma pessoa ciumenta; [...] o acusado dizia que se a vítima não fosse dele não seria de mais ninguém. (Autos $\mathrm{n}^{\circ}$ 000.7318.xxx, segredo de justiça).

Neste trecho que transcreve parte do depoimento das testemunhas, é possível destacar novamente uma característica muito comum nas vozes dos processos que tratam da violência contra a mulher e que consiste no fato de que $o$ agressor faz muitas ameaças na tentativa de intimidar, de calar a voz da vítima e evitar que seja denunciado. Expressões como ...afirmava que iria matar... ofendia verbalmente... efetuava as ameaças... são locuções verbais que corroboram a tentativa de chantagem, de advertência, de intimidação, sendo comum nos casos de violência de gênero. Aqui se percebe a cultura machista. A violência contra a mulher é utilizada como uma forma de sustentar o homem em uma posição de superioridade, fazendo com que o mesmo figure como gênero dominante na relação.

Finalmente, na Decisão e seus Fundamentos, página 11, é possível extrair o seguinte trecho:

"[...] esse comportamento indica o inconformismo do réu com o término do relacionamento, motivação tida como vil para que alguém decida ceifar a vida de outra pessoa. (Autos no 000.7318.xxx, segredo de justiça)".

A visão machista e preconceituosa está enraizada na sociedade moderna, provocando situações inimagináveis. Também o ciúme é responsável por situações de agressão e violência. No caso aqui analisado, a agressão foi 
motivada pelo inconformismo do agressor com o fim do relacionamento. 0 adjetivo vil foi utilizado a fim de demonstrar o motivo insignificante que motivou a agressão, levando a vítima a óbito. O emprego do verbo ceifar em lugar de tirar revela que o operador do direito, levado pela emoção, utiliza o termo que Ihe parece mais apropriado à situação, deixando transparecer as nuances emotivas do momento relatado.

Numa análise do emprego do léxico nos discursos jurídicos extraídos das sentenças da Vara Maria da Penha no combate à violência doméstica contra a mulher é possível perceber como os agressores, em geral, utilizam as palavras com a finalidade de magoar, ofender, colocar a vítima em condição de inferioridade, ao mesmo tempo em que tendem a proferir ameaças, desestimulando as denúncias e os pedidos de socorro.

\section{Considerações}

A linguagem surge da interação, da comunicação entre os seres humanos, sendo determinada social e historicamente, razão pela qual a língua varia de acordo com a região, a cultura, e a sociedade. Justamente pelo fato de ser social, a língua é variável, mutável, e não estática.

Cada uma, e todas as pessoas, ocupam um papel na sociedade, e isso faz parte da significação. Neste sentido, o mecanismo de qualquer formação social tem regras de produção que ditam a relação ente as situações concretas e as posições dessas situações no interior do discurso.

As formações discursivas são formações componentes das formações ideológicas, determinando o que pode e o que deve ser dito a partir de uma posição em uma determinada conjuntura. Isso significa dizer que as palavras mudam de sentido ao passarem de uma formação discursiva para outra, pois muda, igualmente, sua relação com a formação ideológica.

Neste sentido, percebe-se a importância das palavras em toda e qualquer relação social. Nas relações pessoais e afetivas, especialmente, ganham força e são frequentemente utilizadas para expressar o carinho, a 
admiração o estado emotivo. Mas podem ser utilizadas, igualmente, de maneira pejorativa, com a intenção de magoar, ofender ou discriminar. É o que se verifica, por exemplo, nos discursos que envolvem relações de violência de gênero, e cujas ações tramitam e são analisadas pela Vara Maria da Penha, de Londrina. Um enunciado, para ter poder de ação e de transformação da realidade, deve ser pertinente à situação comunicacional. É pelo uso da linguagem que o locutor procura impor sua vontade e os sentimentos exprerienciados são marcados pela escolha lexical.

A Lei Maria da Penha estimulou o avanço de mecanismos hábeis a prevenir e punir qualquer forma de violência doméstica, fazendo valer os direitos da mulher, sua dignidade, mas, principalmente, criando uma cultura no sentido de desconsiderar o homem como símbolo do poder familiar, que exigia respeito e submissão. Por mais que a Lei Maria da Penha ampare e dê proteção à vítima, ainda assim, em muitos casos, o judiciário não consegue impedir o pior.

A ciência jurídica encontra na linguagem a sua possibilidade de existir, utilizando o discurso como uma ponte entre a sociedade e o universo forense. Para que esta possibilidade de comunicação se efetive, a linguagem precisa estar ao alcance das partes e os recursos sintáticos, semânticos e lexicais do discurso devem ser os aliados do locutor a fim de efetivar a função social do direito, que é a efetivação do acesso à justiça em todas as suas esferas. Assim, a carga emotiva presente nas escolhas lexicais das vozes presentes nos processos que envolvem violência doméstica deve servir como um alerta, como um incentivo para que mulheres que passam por essas situações encontrem forças para denunciar o agressor, bem como servir para evitar que outras mulheres caiam nessa teia, nesse jogo psicológico que visa à submissão e à degradação humana.

\section{Referências}


BRASIL. Lei no 11.340, de 7 de agosto de 2006. Lei Maria da Penha. Cria mecanismos para coibir a violência doméstica e familiar contra a mulher... Disponível em: <http://www.planalto.gov.br/ccivil_03/_ato20042006/2006/lei/l11340.htm>. Acesso em 27 de março de 2017

BRITO, Diná Tereza de. Linguagem: o poder no discurso jurídico. Diálogo e Interação, Cornélio Procópio, v. 1, p. 1-10, 2009. Disponível em: <http://www.faccrei.edu.br/dialogoeinteracao>. Acesso em: 27 mar. 2017.

BRITO, Diná Tereza de; PANICHI, Edina. Crimes contra a dignidade sexual: a memória jurídica pela ótica da estilística léxica. Londrina: EDUEL, 2013.

CÂMARA, Joaquim Mattoso. Contribuição à estilística portuguesa. 3. ed. Rio de Janeiro: Ao Livro Técnico, 1978.

CANEZIN, Claudete Carvalho; PANICHI, Edina Regina Pugas. Discurso jocoso em músicas que incitam a violência contra a mulher: materialidade linguística. In: CONGRESSO INTERNACIONAL DE LINGUÍSTICA E FILOLOGIA, 2., CONGRESSO NACIONAL DE LINGUÍSTICA E FILOLOGIA, 20.; 2016, Rio de Janeiro. Anais... Rio de Janeiro: Círculo Fluminense de Estudos Filológicos e Linguísticos, 2016a. Disponível em: <http://www.filologia.org.br/xx_cnlf/.>. Acesso em: 20 mar. 2017.

CANEZIN, Claudete Carvalho; PANICHI, Edina Regina Pugas. Lei Maria da Penha: um estudo sob a ótica da semântica argumentativa. In: CONGRESSO DE ESTUDOS DA LINGUAGEM - CONELIN, 4., 2016, Cornélio Procópio. Anais... Cornélio Procópio: UENP, 2016b.

CRUZ, Isabel Cristina Fonseca da. A sexualidade, a saúde reprodutiva e a violência contra a mulher negra: aspectos de interesse para assistência de enfermagem. Revista Escola de Enfermagem da USP, São Paulo, v. 38, n. 4, p. 448-457, dez. 2004.

FERRAZ JÚNIOR, Tércio Sampaio. Introdução ao estudo do direito: técnica, decisão, dominação. 7. ed. São Paulo: Atlas, 2013.

FERREIRA, Aurélio Buarque de Holanda. Novo dicionário Aurélio da língua portuguesa. Disponível em: <https://dicionariodoaurelio.com/>. Acesso em: 20 mar. 2017.

FIGUEIREDO, Roberta Menezes. Estilo e discurso jurídico: uma análise semiótica do gênero acórdão. Três Corações - MG: Universidade Vale do Rio Verde, 2015.

FUZER, Cristiane; BARROS, Nina Célia de. Processo penal como sistema de gêneros. Linguagem em (Dis)curso: LemD, v. 8, n. 1, p. 43-64, jan./abr. 2008. 
LANGREY, Roger. Mulheres espancadas: fenômeno invisível. São Paulo: Hucitec, 1980.

LAPA, M. Rodrigues. Estilística da língua portuguesa. São Paulo: M. Fontes, 1982.

MAGAL, Sidney. Se te agarro com outro te mato. 1977. Disponível em: <https://www.letras.mus.br/sidney-magal/324300/>. Acesso em: 11 mar. 2017.

MARCONDES FILHO, Ciro Juvenal Rodrigues. Contra a banalização da violência. In: ENCONTRO LATINO-AMERICANO DE FACULDADES DE COMUNICAÇÃO SOCIAL, 10., São Paulo, 2000. Anais... São Paulo: USP, 2000.

MARCUSCHI, Luiz Antônio. Cognição, linguagem e práticas interacionais. Rio de Janeiro: Lucerna, 2007.

MARTIN, Marcel. A linguagem cinematográfica. São Paulo: Brasiliense, 2003.

MARTINS, Nilce Sant'Anna. Introdução à estilística: a expressividade na língua portuguesa. 4 ed. São Paulo: EDUSP, 2012.

MONTEIRO, José Lemos. A estilística. São Paulo: Ática, 1991.

MONTEIRO, José Lemos. $A$ estilística: manual de análise e criação do estilo literário. 2 ed. Petrópolis-RJ: Vozes, 2009.

REI, Cláudio Artur; SIMÕES, Darcila. Língua e estilo: uma tessitura especial. In: OLIVEIRA, Ester de; SILVA, Suzete (Org.). Semântica e estilística: dimensões atuais do significado e do estilo: homenagem a Nilce Sant'Anna Martins. Campinas, São Paulo: Pontes, 2014.

SAUSSURE, Ferdinand de. Curso de linguística geral. Tradução de Antônio Chelini, José Paulo Paes e Izidoro Blikstein. 24. ed. São Paulo: PensamentoCultrix, 2002.

SOUZA, Ednilsa Ramos de. Violência social: um desafio para os serviços de saúde pública. Saúde em Foco, Rio de Janeiro n. 13, p. 2-3, 1996.

VERÍSSIMO, Luís Fernando. Diminutivos. Disponível em: <http://intervox.nce.ufrj.br/ jobis/l-dimi.htm>. Acesso em: 22 mar. 2017.

VILANOVA, José Brasileiro. Aspectos estilísticos da língua portuguesa. Recife: Ed. UFPE, 1984. 